\title{
A consolidação do campo disciplinar da Ciência da Informação: exaustão das discussões ou necessidade de entendimento de regimes institucionalizantes?
}

Para o início deste editorial, compartilho a seguinte indagação: será mesmo que determinadas temáticas estão esgotadas em suas discussões? Como esclarecimento, considera-se ser essa questão um ponto determinante, muitas vezes, para a escolha de investigações pelos agentes científicos (BOURDIEU, 1983), levando em conta, a natureza característica de cada campo disciplinar. Considerando as dinamicidades e as intercorrências presentes na construção das ciências (FOUREZ, 1995), estudos voltados à consolidação do campo disciplinar da Ciência da Informação, provavelmente, nunca devem se esgotar.

Como sugere a Associação de Pesquisa e Pós-Graduação em Ciência da Informação (ANCIB), em ementa propositiva do grupo de trabalho 'Estudos Históricos e Epistemológicos da Ciência da Informação', um volume considerável de caminhos são sugeridos para os estudiosos dessa área: estudos históricos e epistemológicos da Ciência da Informação; constituição, desenvolvimento e inovação conceitual, teórica e metodológica do campo científico informacional; os objetos de estudos da Ciência da Informação e suas transformações teórico-conceituais; reflexões e discussões sobre disciplinaridade, interdisciplinaridade e transdisciplinaridade. Verifica-se que esses estudos possuem uma tradição em determinadas linhas pesquisa em cursos de pós-graduação no Brasil, presença de grupos de pesquisa específicos, fortalecimento de laços interdisciplinares, e/ou, até mesmo, interdominiais (MELO, 2020; BUFREM; FREITAS, 2015).

Reconhecido como maior evento da pós-graduação em Ciência da Informação no Brasil, o Encontro Nacional de Pesquisa em Ciência da Informação, teve, até sua vigésima edição, por meio de onze grupos de trabalho, aproximadamente, 4720 comunicações científicas (artigos e pôsteres), estando o número de trabalhos submetidos e aprovados em crescimento contínuo desde 2010. Esse indicador é um importante parâmetro para se poder afirmar: mesmo diante de temáticas já discutidas, novas escolhas de objetos de investigação e aplicações metodológicas podem resultar em variadas conquistas científicas para o campo disciplinar da Ciência da Informação, a saber, a expansão de sua dimensão cognitiva composta por conceitos, teorias, problemas e métodos (WHITLEY, 1974).

Voltando para o específico caso dos estudos sobre a consolidação do campo disciplinar da Ciência da Informação, sob a ótica da institucionalização cognitiva, destaca-se que esse segue em fase de ampliação de seus objetos de pesquisa, desde o final da segunda guerra mundial. Nota-se uma variedade de investidas, desde epistemológicas (HJØRLAND, 2015) até as que respondam aos anseios mais diretos de uma sociedade e de uma época (ARAÚJO, 2018). Mas esse campo disciplinar não se limita a sua dimensão cognitiva, e, nesse intuito, para entender a Ciência da Informação, urge a necessidade de compreensão de regimes institucionalizantes, sendo esses postos em uma perspectiva plural e multidiversifica- 
da de pesquisa, fugindo das tradicionais análises dos agentes, instituições e dos registros intelectuais disciplinares.

Trazendo uma crítica voltada à necessária evolução dos modos de se produzir e comunicar a ciência, Shinn $(2000,2008)$, por meio de controvérsias sobre a atividade científica, propõe o entendimento dos campos disciplinares atendendo à observação de quatro regimes: o regime disciplinar, preocupando-se com os agentes, instituições e registros intelectuais; o regime utilitário, com a apreensão da ciência aplicada; o regime transitório, com a percepção dos movimentos dos agentes científicos entre campos disciplinares distintos; e o regime transversal, verificando a presença de multiplicidade de identidades e trajetórias intersticiais entre agentes científicos que compõem um campo disciplinar.

A perspectiva da sociologia transversalista da atividade científica se apresenta como superação às concepções de ciência universal e socialmente neutra (pós-grandes guerras e final da década de 1980) e de ciência socialmente contextualizada (1990 - atual) (VELHO, 2010). Trata-se de um sistema de compreensão que ousa permitir, em teoria, dar conta dos fenômenos de convergência intelectual, levando em conta a diversidade, a heterogeneidade, a contextualidade das práticas cognitivas e concretas, investindo para isso na proposição de construção de um quadro de análise que permita apreender a autonomia relativa dos campos disciplinares como resultado de forças transversais que o atravessam e o ligam aos outros campos sociais.

Porém, adianta-se, o instinto positivista, sedento pelas práticas ligações possíveis e capazes de apreender uma visão realista e dinâmica dos acontecimentos (BADIOU, 1972), pode se frustrar ao verificar que as investidas teóricas de Shinn (2008), como o próprio autor afirma, tratam-se de algo, ainda, inicial. E nesse sentido, para a percepção dos regimes de produção e circulação da ciência no campo disciplinar da Ciência da Informação, faz-se necessário ir além da obediência teórica proposta na perspectiva transversalista.

Com isso, em aspecto amplo, sugere-se: sejam sensíveis à percepção da ciência como resultado de processo dialético de construção histórica proposto por diversas frentes, vindas de variados campos da sociedade. Além dos regimes acima descritos, será admissível apreender, de forma mais clara, possíveis mecanismos capazes de interagir de maneira significativa com os modos de produção e circulação da ciência, caracterizando-a de forma única. É possível, dessa forma, a sugestão de uma representação mais dinâmica e realista do campo disciplinar da Ciência da Informação.

Trazendo esta provocação, parafraseio Eco (2008), e interpreto que o pesquisador precisa concordar com seus interesses e paixões de pesquisa. Certos medos devem ser extirpados, defendo que nenhuma discussão temática está finalizada, que não merece o devido revisamento, que não merece ser apropriada a novos objetos e métodos. Finalizando, agradeço o espaço na Ciência da Informação em Revista, em especial aos editores e amigos Edivanio Duarte de Souza e Ronaldo Ferreira de Araújo.

\section{REFERÊNCIAS}

ARAÚJO, C. A. A. O que é Ciência da Informação. Belo Horizonte: KMA, 2018.

BADIOU, A. Sobre o conceito de modelo: introdução a uma epistemologia materialista das matemáticas. Lisboa: Editorial Estampa, 1972. 
BOURDIEU, P. O campo científico. In: ORTIZ, R. (Org.). Pierre Bourdieu: sociologia. São Paulo: Ática, 1983a. cap. 4, p. 122-155.

BUFREM, L. S.; FREITAS, J. L. Interdomínios na literatura periódica científica da ciência da informação. Datagramazero, v. 16, n. 3, ago., 2015.

ECO, U. Como se faz uma tese. 21 ed. São Paulo: Perspectiva, 2008.

FOUREZ, G. A construção das ciências: introdução a filosofia e à ética das ciências. São Paulo: Editora da Universidade Estadual Paulista, 1995.

HJØRLAND, B. Informetrics needs a foundation in the theory of Science. In: SUGIMOTO, C. (Org.) Theories of Informetrics and Scholarly Communication. Berlin: Walter de Gruyter, 2015.

MELO, W. M. O processo de institucionalização científica na Ciência da Informação do Brasil: um campo disciplinar sob a perspectiva transversalista. 2020. $264 \mathrm{f}$. Tese (Doutorado em Ciência da Informação) - Programa de Pós-Graduação em Ciência da Informação, Universidade Federal de Pernambuco (UFPE), Recife, 2020.

SHINN, T. Axes thématiques et marches de diffusion: la science en France, 1975-1999. Sociologie et societés, v. 32, n. 1, p. 43-69, 2000.

SHINN, T. Regimes de produção e difusão de ciência: rumo a uma organização transversal do conhecimento. Scientiae Studia, São Paulo, v.6, n.1, p. 11-42, 2008.

VELHO, L. M. L. S. Modos de produção de conhecimento e inovação. Estado da arte e implicações para a política científica, tecnológica e de inovação. In: CENTRO DE GESTÃO DE ESTUDOS ESTRATÉGICOS (CGEE). Nova geração de política em ciência, tecnologia e inovação: seminário internacional. Brasília: CGEE, 2010b. cap. 2, p. 23-40.

WHITLEY, R. Social processes of scientific development. London: Routledge and Kegan, 1974.

\section{Willian Lima Melo}

Doutor em Ciência da Informação (UFPE)

Professor do curso de Biblioteconomia

Universidade Federal de Alagoas

willianmelo23@gmail.com 